\title{
LA TRADICION DEL FOLLETÍN Y DE LA NOVELA POPULAR EN CHILE (CÁNON Y CORPUS EN LA NARRATIVA CHILENA SIGLOS XIX Y XX)
}

\author{
Eduardo Barraza \\ Universidad de Los Lagos, Osorno, Chile \\ ebarraza@ulagos.cl
}

\section{RESUMEN / ABSTRACT}

Calificado como literatura de masas, subgénero o para-literatura, el folletín aparece situado en la periferia del canon y de la crítica de nuestra literatura. Tal subordinación hace necesario indagaciones que permitan establecer un campo de investigación que contribuya a sistematizar los rasgos estructurales propios de esta narrativa en Chile. El folletín no se reduce simplemente a una "narrativa anacrónica" (Herlinghaus 2002) que somete a un público masivo bajo "el imperio de los sentimientos" (Sarlo 1985) y a variadas ocasiones para "hacer llorar". A nuestro juicio, se trata de una constante textual -que Eco identifica como "novela popular", que pone en juego "una práctica de la consolación" (2012)- no ajena a cuestiones sociales, políticas y utópicas, ni a la carnavalización o desacralización del género, según examinaremos a propósito de La casa de los espíritus (1982) de Isabel Allende y El viaducto (1994) de Darío Oses.

PALABRAS ClAVE: narrativa chilena, canon, corpus, folletín, novela popular.

\section{The Tradition of the Serial Novel and the Popular Novel in Chile (Canon and Corpus in Chilean Literature. Nineteenth and Twentieth CENTURY)}

Identified as mass literature, subgenre or paraliterature, the serial novel appears located in the periphery of the canon and of the literary criticism. Such subordination encourages examination that contributes to establish a field of research that makes it possible to categorize the structural features of that type of narrative in Chile. The serial novel is not simply reduced to an "anachronistic narrative" (Herlinghaus 2002) that subordinates a mass audience to "the empire of feelings" (Sarlo 1985) and occasionally to "provoke tears". In our view, it is a textual constant, which Eco identifies as the "popular novel", that brings into play "a practice of consolation" (Eco 2012), not alien to social, political and utopian questions, nor 
to the carnivalization or demystification of the genre, as we will examine with regard to La casa de los espíritus (1982) by Isabel Allende and El viaducto (1994) by Dario Oses.

KEYWORDS: Chilean literature, canon, corpus, serial novel, popular novel.

Recepción: 26/04/2017

Aprobación: 31/07/2017

\section{INTRODUCCIÓN. LA TRADICIÓN DEL FOLLETÍN EN CHILE}

En general, la narrativa chilena no es ajena a la circulación y consumo de folletines. Por lo mismo, dado que se trata de un corpus que en la actualidad se presenta bajo múltiples formatos, es preciso atender a la necesidad de sistematizar los rasgos estructurales propios de la narrativa de filiación folletinesca en Chile - entre los siglos XIX y XX-con el fin de clarificar su verdadero lugar en la evolución del canon literario y, eventualmente, discutir el juicio de la crítica.

A mediados del siglo XIX, los periódicos chilenos compiten para publicar -al pie de sus portadas- sucesivos folletines, principalmente de exitosos autores franceses. Al respecto, postulamos que la influencia de tales prácticas escriturales no es ajena -en diverso grado- a los fundadores de nuestra narrativa, sea el caso de Lastarria o de Blest Gana ${ }^{1}$. Se trata de una serie fundacional en la cual el azar y el motivo del amor impedido actúan como una estructura modélica para un gran sector de la narrativa chilena (Barraza $2012,2015)$. En esta fase inaugural, el círculo del deseo amoroso está ligado a un marco socio-político en que "el amor y el patriotismo" eran tributarios de un rango sacrificial que implicaban los proyectos nacionales (Sommer 2004; 2006). Cuando en 1864, A. Blest Gana declara que desea ser un novelista como H. de Balzac, no ignora los formantes realistas y folletinescos de su

En De los medios a las mediaciones, (2013: 133 y ss.), Martín-Barbero ha efectuado un sistemático panorama del folletín desde antes de su prototipo aparecido en los periódicos de Francia (versos de ciego, colportage, literatura de cordel, etc.). Para el caso de Chile, uno de sus precedentes se encuentra en una carta del 21 de mayo de 1813, cuando un lector solicita a El Monitor Araucano que le publiquen (en sucesivos números) El abrazo del gigante. A este título se suma, en 1831, una inconclusa Historia de un mazo de tabaco escrita por él mismo de la cual se publicaron solo cuatro "entregas" en el Diario La Opinión, № 26, 27, 28 y 30. Foresti, C. (2009): 104-105; 107-125). 
modelo y paulatinamente lo replica, publicando primeramente sus novelas en periódicos como El Museo y La Voz de Chile.

Anteriormente -y situado desde el centro de la élite letrada del siglo XIXen 1862, A. Blest Gana sostiene desde Martín Rivas que la tesis de su novela difiere de aquella del folletín en el cual la sociedad gira "en un círculo que se llama amor y...tiene por centro el ángel que se apellida mujer" declarándolo como lectura de consumo apta para "mujeres y tenderos" $(1973: 45,76)$. Por lo demás, es notorio que -aparte de Blest Gana- los narradores del siglo XIX propiciaron diversos e innovadores motivos con o sin el formato del folletín, como aquellos del amor impedido por razones sociales, circunstancias históricopolíticas o de exclusión étnica ${ }^{2}$ en el marco de lo que hemos denominado las "libertades de la novela liberal" (Barraza 2004, 2013).

No obstante, el canon literario atiende preferentemente a la presentación del folletín como un subproducto de ficción fronterizo situado en un espacio que corresponde al tercio inferior de la primera plana del periódico (denominado "feuilleton") y, por lo mismo, contaminado con los textos informativos o de no ficción, comerciales y misceláneos propios del diario en el cual día a día se publica. Por lo demás, se trata de textos cuyo origen corresponde a un contrato convenido entre el dueño del periódico y el escritor. Esta condición ("mercantil") del folletín -mediante la cual "imitando a la culta Europa" se incentivan y facilitan las suscripciones- transgrede ("escandaliza", más bien) el canon que entiende la literatura como oficio no sometido al lucro, tanto como los hábitos de una lectura sucesiva no fragmentada ni discontinua. El hecho es que, promediando el siglo XIX, Chile presenta un preciso contexto histórico y societal en el cual el folletín constituye una de las prácticas de lecturas cultural y socialmente existentes (Poblete 2003: 37-38). En términos de Eco, se trata del esbozo de un momento histórico que durante el siglo XX será conocido como "la sociedad de masas", instante en el cual "el estrato

2 Durante el siglo XIX, el periódico La Estrella de Chile publica una serie de narraciones de tema indígena (Foresti 2001). Al respecto, aparte de los motivos del "amor posible" e "imposible" que desarrollan Blest Gana y Lastarria, un ciclo especial se configura en torno a textos como Cailloma, Leyenda indiana (1870) de Raimundo Larraín; Gualda (1870) y A orillas del Bío-Bío (1870) de Máximo Lira; Huincahual (1888) de Alberto del Solar; Mariluán (1862) del propio Blest Gana. En ellos, se codifica que la diferencia étnica es un obstáculo imposible de superar, por cuanto la norma social privilegia un matrimonio inter pares- que se encubre tras el rigor de un fatum histórico (Barraza 2004; 2013). 
popular ingrese como protagonista en la vida social (y cultural) y participe en las cuestiones públicas"'.

Por lo mismo, en el siglo XIX, las polémicas sobre "las lecturas validadas socialmente" (Poblete 2003) no estarán distantes de los debates inaugurales sobre la formación del canon literario nacional. En 1861 -en su Discurso de Incorporación a la Universidad de Chile-A. Blest Gana concuerda en que a la fecha "[1] a afición a la lectura ha ganado inmenso terreno" (Promis 1977: 120). En tal discurso se manifiestan las bases teóricas de una narrativa (de notoria filiación folletinesca) que recientemente el autor había puesto en práctica en La aritmética en el amor (1860). Sin embargo, en esta ocasión el novelista mantiene una prudente distancia respecto al folletín, aunque tácitamente se refiere a él cuando hace mención a una "muchedumbre de novelas europeas puestas a tan bajo precio por la industria moderna, en manos de los lectores" (en Promis 1977: 120).

Pero, en este contexto, el éxito del folletín no es simplemente un asunto de competencia o de mercado sino que implica, igualmente, un juicio éticoestético. A. Blest Gana critica que los "folletines" "han viciado el buen gusto" (en Promis 120-121). Sin embargo, cuando A. Blest Gana se refiere a la novela nacional "realista, social y de costumbres", lo hace en términos no distantes de las estrategias de compensación propias del folletín (tránsito del amor imposible a un amor posible que supera las diferencias sociales, finales felices y consoladores). Por lo demás, el mismo A. Blest Gana debió afrontar, en 1853, el juicio de la Revista Católica (N³30/21 de octubre) que criticó Una escena social (una de sus novelas-folletines publicada en el Diario El Museo). La mencionada revista le reprocha que su novela está "infestada de fatalismo, preñada de incidentes amorosos, de lances provocativos, de impúdicas pinturas muy a propósito para exaltar la fantasía y despertar en el corazón de la inexperta juventud la pasión más peligrosa y seductora que en él pueda albergarse" (en Poblete 2003: 36-37, nota 39).

Resulta, así, que el folletín aparece con un signo de interdicción ético y estético tanto en las esferas episcopales como en el canon literario nacional (Poblete 2003: 33). Sin embargo, promediando el siglo XX, aunque Raúl

Sin embargo, discute Eco, paradójicamente, "el modo de divertirse, de pensar, de imaginar (de las masas) no viene de abajo: a través de las comunicaciones de masas todo ello le viene impuesto a la manera de mensajes formulados según el código de la clase hegemónica" (Apocalípticos 30). (El paréntesis es nuestro). 
Silva Castro - a raíz del éxito de Adiós al Séptimo de Línea- intuye que "el gusto por el folletín no ha dejado totalmente de existir en el público", no deja de calificarlo como una "forma degenerativa" (1961: 197, 339). No obstante, una actitud neutral se observa en C. Goic cuando destaca que durante el "criollismo", el folletín puso "una nota particular" y fue afectado "muy directamente" por el naturalismo (Brevísima relación 1973: 30). Por otra parte, el juicio canónico resalta la caracterización normativa del folletín como un mundo desaforado: 'seducción por la pasión amorosa, fatalismo, esquematismo de los personajes, inverosimilitud, reconocimiento del origen', rasgos genéricos considerados más que suficientes para establecer la condición periférica de un (sub)género que pareciera no provocar mayores reflexiones teóricas. Como concluye J. Poblete, a propósito de A. Blest Gana, a partir del siglo XIX la novela chilena "intentará ser simultáneamente una obra popular como los folletines, una obra moderna y seductora como las novelas europeas, una obra seria como las que merecen el apoyo del gobierno (y del canon), una obra original en su apropiación textual de las costumbres nacionales; y por último, una obra de educación de aquellos que la favorezcan con su lectura" (2003: 55).

\section{DEL SIGLO XIX AL SIGLO XX}

Salvo la activa intervención de D.F. Sarmiento en la polémica sobre el consumo de folletines en Chile - publicándolos y dando a conocer reseñas, comentarios y artículos desde las páginas del Diario El Progreso (18421845) - el folletín no originó mayor atención para definir su canon frente a la novela nacional que propiciaba la elite culta de la generación literaria de 1842, por ejemplo. Las demandas de Lastarria y Blest Gana respecto a satisfacer la función moral de la literatura no distan mucho de aquellos de la Revista Católica relativos al folletín- ya citados-si se tiene presente que, en opinión de A. Blest Gana, el novelista debe cuidar "la moralidad"... "sin desvirtuar su misión y sin exponerse a la justa censura de la crítica y el desprecio" del lector (en Promis 125). Por otra parte, pareciera que -al contrario de un notorio listado de autores de "folletines", según consignan C. Foresti (1999, 2001); J. Poblete (2003); Silva Castro (1961)- la novela propiamente tal no contaba con muchos representantes. Así se puede concluir desde el momento que debió ser postergada (en 1859) una convocatoria para escribir "una novela histórica o de costumbres" hecha por la Universidad de 
Chile que prácticamente contó con dos concursantes, entre los que se contaba Alberto Blest Gana. Con Durante la Reconquista (1897), el folletín continúa su marcha (entre dos aguas: novela/historia) hacia el siglo XX de la mano de Blest Gana, novela que actualiza los juicios genéricos y negativos respecto a la narrativa folletinesca por parte de R. Silva Castro y Pedro Nolasco Cruz (en Poblete Varas 1968: 221 y 218).

Conforme estos precedentes, no resulta extraño que en el curso del siglo XX se enfatice la condición del folletín como literatura-escritura de masas, subgénero o para-literatura, lo cual conlleva a situarlo en las "fronteras de lo literario" (Boyer 1992; 1995), al margen o en la periferia del canon y de la crítica de nuestra literatura, aunque no al margen de sus masivos lectores, según hasta aquí hemos planteado. Por lo demás, resulta notorio que -aparte de las distinciones honoríficas y de mercado otorgadas a los autores de este género- el éxito, prestigio o aval per se de la narrativa de filiación folletinesca deriva de alcanzar (al igual que cualquier otra obra situada en el canon) la condición de best seller. Este hecho implica que se originen inevitables debates respecto a "legitimar el valor" o "la calidad de la literatura popular de tradición folletinesca" (García Canclini, Lectores 26). Se trata de una calificación que -conforme al canon-debe ser conferida por actores específicos, tales como jurados expertos o por la propia academia, hecho que implica la reflexión teórica sobre la índole y el valor de una escritura subestimada como propia de un "canon bastardo" o de una "estética bastarda" (Matus 2004)4. Tales demandas teórico-metodológicas -más allá del mercado- están orientadas en favor de la adecuada legitimación y consideración de esta narrativa en los debates relativos al campo literario o artístico conforme a su particular jerarquía (Bourdieu 1989-1990; García Canclini, Lectores 26). Provisionalmente, tal "des-marcación" o "fuga" del folletín -entendida, aquí, como "salida de la periferia y aproximación a los límites del canon"- se expresa cuando se le asigna a la literatura popular de tradición folletinesca un locus propio en las llamadas "bibliotecas escolares" (CRA) o en las "colecciones juveniles" de diversas editoriales. No obstante, esta aproximación del folletín a las inmediaciones del canon se hace mediante la designación genérica de "novela", cuando no de "novela popular"-como

\footnotetext{
"Me han basureado", es el reproche que dirige Isabel Allende al pleno de la academia con ocasión de ser designada Doctora Honoris Causa por la Universidad de Santiago (2015).
} 
propone Eco- porque no es frecuente que el folletín se designe como tal ni que los autores quieran ser adscritos a tal práctica escritural ${ }^{5}$.

\section{MUDAS Y NUEVOS SOPORTES DEL FOLLETÍN EN EL SIGLO XX}

Un exhaustivo registro de "folletines literarios" publicados en diarios de Santiago y Valparaíso entre los años 1830 y 1925 da cuenta del predominio en Chile de los folletines europeos (Herrera 1998). Sin embargo, progresivamente, la industria editorial (Nascimento, Zig-Zag, Ercilla) impone la circulación de la "novela", propiamente tal, como producto canónico que compite con el auge de la publicación de folletines sentimentales del siglo anterior. Tempranamente -en Juana Lucero (1902)-Augusto D'Halmar opta por un "romance real" (1952: 19) en tanto que la protagonista expresa su decepción por las "mentirosas historias sentimentales" $(143,256)$. Por lo demás, la fundación de la Sociedad de Escritores de Chile (1931) y la creación del Premio Nacional de Literatura (1942) afianzan el canon literario cuyo referente, desde 1885, era la Academia Chilena de la Lengua. A lo anterior se suman a lo largo del siglo, las intensas polémicas literarias y una sostenida producción de las escuelas narrativas (criollista, mundonovista, neorrealista, irrealista) que imponen sus fueros frente a un extenso número de folletinistas chilenos cuyos nombres perdurarán en el anonimato. Por otra parte, en el curso del siglo XX, el folletín tradicional experimenta una sucesión de mudas en su formato. El tradicional soporte del periódico sufrirá la competencia que provoca la emergencia de los mass media. Por esta vía, paulatinamente, el folletín dejará paso a la "novela por entregas" (Ferreras 1972) o será publicado en revistas magazinescas y en semanarios que serán desplazados prontamente por las radio-novelas, bestsellers y series del cine y de la televisión. El hecho es que -promediando el siglo XX-aunque el lector tradicional se vea emplazado como auditor y espectador, continuará hablando de "su novela" o de la "comedia radial".

\footnotetext{
Por excepción, aparecen tales designaciones en Emelina (1886) de Rubén Darío y en Golondrina de invierno (1912) de Víctor Domingo Silva. En entrevista con Rodríguez Monegal, Manuel Puig declara que debió polemizar con sus editores para que Boquitas pintadas llevara el rótulo de "folletín" (1972). Por el contrario, hacia 1950, Adiós al Séptimo de Línea de Jorge Inostrosa enmascara su condición de folletín radial por entregas para convertirse en una "novela histórica-sentimental" que circulará en cinco tomos, al contrario de la reducida extensión -de bolsillo- que predomina en la novela de tradición folletinesca del siglo XX.
} 
Siguiendo a Eco, se trataría de una incipiente puesta de los "bienes culturales" a disposición del público, hecho que permite "el acceso de las clases subalternas al disfrute de los bienes culturales (Apocalípticos 15) mediante la puesta en mercado de productos masivos propios de la industria cultural. Por tal razón, el folletín tradicional -claramente identificable y criticado en el siglo XIX- experimentará un proceso de "hibridación textual" en el siglo $\mathrm{XX}^{6}$ y será conocido genéricamente como novela histórica sentimental, novela popular, romance, novela escolar-juvenil, escritura que puede ser practicada en diverso grado por aquellos "novelistas" que participan del canon, según comprobamos en el amplio corpus textual del folletín 7 .

Es así como Rodrigo Cánovas puede plantear que el folletín es "una de las grandes formas culturales de la narrativa chilena" de fines del siglo XX (Novela chilena 2002: 267). No obstante, a su juicio, se trata de una escritura que "convoca a un lector masivo de gustos antiguos, lleno de nostalgia" (267). Se trataría, entonces - antes que de una "narrativa anacrónica" (Herlinghaus 2002) o de una simple reescritura del folletín decimonónico- de una implícita genealogía y actualidad de esta serie por cuanto, a juicio de Eco, 'la novela actual es nieta del folletín' (El superhombre 19) de modo tal que -como ratifica Amar Sánchez- "esta forma 'baja' por definición, ha sido fundamental

$6 \quad$ El corpus de la narrativa popular de filiación folletinesca establece cohesionadas relaciones intertextuales e intratextuales consigo misma y con el canon institucionalizado. Por lo pronto, observamos que mediante discursos paratextuales, como el título, la novela popular enfatiza su condición de narración folletinesca/sentimental (Palomita Blanca), que recurre a epígrafes procedentes de la escritura canónica como la de Neruda (La casa de los espíritus), Cardenal (Dónde estás, Constanza...), Pedro Prado (Francisca, yo te amo), León Felipe (Gracia y el forastero). Es una serie que polemiza frente al tradicional canon escolar como aquel del Poema del Cid o el de La vida es sueño según los indicios que se presentan en La Beatriz Ovalle. Tampoco posterga su propio canon como es el caso de las referencias a Huckleberry Finn, Coseta, según El Metrogoldin de J.L. Rosasco o a Los Miserables de Víctor Hugo, uno de los leit motivs de Dónde estás, Constanza, de Rosasco. Mucho menos le son ajenos aquellos imaginarios procedentes de la cultura de masas como el cine y el comic (Tarzán), las canciones populares (tangos, boleros).

Conforme a su corpus, el folletín actual se instituye como un "canon alternativo" (Mignolo 1995:255), propio de una precisa serie narrativa en la cual se hace presente un inevitable "orden del discurso" que deja su impronta en la "historia de la literatura chilena" e incide en un sector de ella en que se traza el perfil y la escritura de la novela nacional. Por otra parte, se trata de un corpus que remite a un tradicional "arte de contar" (Scheherezade) que reproduce en el siglo XIX la condición de escuchar cuando se leen folletines a un público que no sabe leer -o que no puede adquirirlos- o cuando en la sociedad burguesa se llevan a cabo "sesiones de lectura". 
en la conformación de la novela latinoamericana del siglo XX" (1997: 47) tanto que, a la fecha, en la novela canónica habría índices genealógicos de un "proto-folletín" (Cánepa 1988; Arcos 2010). Por lo mismo, no basta con considerar exclusivamente a la literatura popular de filiación folletinesca como una lectura de masas cuyo interés radica en el "motivo del amor impedido" y en el "ilusorio final feliz" que gratifica al lector; o situar a La casa de los espíritus (1982) en el canon, avalada por el prestigio de Cien años de soledad. Según hemos dicho precedentemente, se requiere atender a la naturaleza específica del mundo narrado en el folletín en el cual -aparte de una intriga básica y del esquematismo de los personajes- se lleva a efecto una matriz de significados que ponen en práctica "los artificios del consuelo" (Eco, El superhombre 18-22) no ajena a un contexto historiográfico y político frente a lo cual el socialismo - como el de Sue- también participa de la consolación (El superhombre 39). Por lo mismo, se requiere una sistematización de las perspectivas teóricas que han efectuado -entre otros-autores como Beatriz Sarlo, Jesús Martín-Barbero y Umberto Eco, para efectos de diseñar un paradigma del mundo narrado en la novela popular de filiación folletinesca que en la actualidad haga posible lecturas que validen su matriz de sentido frente al canon literario, a partir del análisis y discusión teórica pertinentes, según reseñaremos a continuación.

\section{EL FOLLETIN Y EL "IMPERIO DE LOS SENTIMIENTOS"}

En el corpus folletinesco, "el tópico del amor impedido" y el tipo de "la mujer angelical" aparecen como formantes de una matriz sentimental sine qua non que rige la narrativa de tradición folletinesca. Sin embargo, los temas y motivos amorosos no son atributos exclusivos del folletín tradicional sino que tienen una precisa tradición clásica (Cabello Pino 2010), cuyo catálogo remite - entre otros hitos- a la tradición de la "novela cortesana" y al "amor cortés". Se trataría, entonces, de un meta-género (Zó 2007) en cuyo corpus se llevan a cabo las diversas variantes del amor posible vs. el amor imposible ${ }^{8}$.

8 En textos como Cuatro Remos, Golondrina de invierno, El mestizo Alejo y La criollita; La Beatriz Ovalle; La casa de los espiritus; Dónde estás Constanza; Francisca, yo te amo; Gracia y el forastero; Adiós al Séptimo de Línea, Palomita Blanca, se encuentran algunas de las variables de este motivo sentimental, en términos de amor imposible y ausencia 
"Un metagénero en el que participan la "novela de tendencia subjetiva", "idealista" o "sentimental" (L. A. Sánchez 1976: 124-148), el "romance", la novela histórica, costumbrista, regional (Zó 80, 92). (E, incluso, la novela policial que no escapa al típico consuelo del final feliz y castigo a los culpables). Sin embargo, ni Sánchez ni Zó mencionan al folletín como una de sus formaciones macrotextuales. Del mismo modo, cuando Beatriz Sarlo (1985) analiza la novela popular/semanal argentina pone de relieve que el "imperio de los sentimientos" es una de las claves del folletín. La fuerza pasional que desencadena el motivo amoroso, dice, "resulta literariamente interesante". Agrega Sarlo que la pasión surge "cuando el sentimiento amoroso encuentra un obstáculo en su camino" a partir de lo cual extrae su carácter trágico y su grandeza, pues se trata de "transgredir en nombre del sentimiento" e imponer una nueva legitimidad que la sociedad no admite. En mayor o menor grado, cuando "los derechos al sentimiento son oprimidos por las trabas sociales... adquieren la capacidad de convertirse en relatos "literarios", afirma, y concluye que "Los hombres (y mujeres) felices no tienen historia" (80-82). (El paréntesis es nuestro).

\section{EL FOLLETÍN: UN UNIVERSO DE TRAMAS SINUOSAS}

En los textos folletinescos -y en este metagénero, en general- el tópico del "flechazo" o del "amor a primera vista" desencadena una dinámica sentimental que se despliega intensamente y provee "un entrecruzamiento de varias intrigas" que generan una densa "trama sinuosoidal", según nomenclatura de Eco (Retórica e ideología 111-114). Tal intensidad sentimental se advierte especialmente cuando el relato se efectúa desde un yo que -situado en el locus de "un círculo del deseo" (Sommer, Un círculo 2006)- narra, recuerda y busca la complicidad del lector para que participe de su nostalgia, de una pérdida amorosa o su infelicidad ${ }^{9}$. Pero, no basta con tal adhesión. La trama

de un final feliz; amor sólo inter pares y rechazo del arribismo; sanción a la infidelidad y adulterio; pérdida de la amada (por alejamiento, muerte, diferencia de clase o de etnia) el amor como apropiación erótica antes que como "opio de las mujeres" (Millet 1984).

La experiencia sentimental propicia el aprendizaje de "escritor", según se revela en La niña azul de J. L. Rosasco, o se traduce en una terapia contra el dolor-como lo ilustra Gracia y el forastero- o permite conjurar los traumas de una violencia originaria como hace Alba, la nieta de Trueba o, presuntamente, Inés de Suárez -en Inés del alma mía de Isabel 
sentimental del folletín debe desplegarse en un doble sentido: convencer al lector-consumidor para que no se aleje de la historia y para que adquiera la próxima entrega. Para tales efectos, en el folletín tradicional, el narrador ordena la acción en torno a una artificiosa cadena de intrincadas e imprevistas situaciones que seduzcan el interés del lector por lo que sobrevendrá en el próximo episodio, manejando a su arbitrio el tópico de la conclusión de cada capítulo. Además, aparte del señuelo de los títulos, los respectivos capítulos llevan subtítulos no menos insinuantes, como se advierte en La casa de los espiritus. Por lo mismo, no extrañará que los periódicos del siglo XIX agreguen un recuento de lo tratado en los capítulos anteriores para contextualizar al lector o se le anticipan incidentes de la próxima entrega, como se reitera en las teleseries actuales (Cfr. Cuatro remos 1971:20).

Martín-Barbero hace notar que la novela popular "conserva la predominancia del relato, del contar a", lo que implica la presencia constante del narrador estableciendo día a día la continuidad... y conserva, también, la apertura indefinida del relato, su dilatada apertura (de la acción) en el tiempo" ( $\mathrm{La}$ telenovela 75). Por lo mismo, el autor de folletines debe manejar con destreza suficiente tal "durabilidad de la historia" para que el narrador pueda encadenar las extensas secuencias de la acción y, al mismo tiempo, pueda manifestar su punto de vista frente al mundo narrado, los personajes y la acción tanto como el sentido de su acto de narrar, gesto que se aprecia en La casa de los espíritus (1982) que consta de dos partes y, particularmente, en Cuatro Remos que consta de seis (1883). Por lo mismo, la predominancia del acto de contar en la novela de filiación folletinesca deviene en el predominio de la acción centrada en una intensa historia de amor que urge narrar, sea ella una "historia inacabable de dolor, de sangre y de amor" (...)-según se reitera en La casa de los espíritus - o de relatos sobre "personas a las que hemos amado y que nos han amado" (1997: 545), como se afirma en La niña azul, de J. L. Rosasco, o se ponga en juego la validez de la premisa conforme a la cual "al amor hay que ganarlo" como hemos advertido en El beso de la mujer araña, de M. Puig (Barraza, Elocución y diseño 1988). En términos de Eco, en el folletín, la mimesis no se reduce a una simple imitación de

Allende- para dar su versión histórico-sentimental de la conquista de Chile. De ahí que en la novela popular domina la memoria del narrador autobiográfico que, llevado por la fuerza sentimental del recuerdo, puede llegar a emitir un discurso dialógico, próximo al monólogo interior, como en Palomita Blanca, o se disgrega en un collage que invade la narración de La Beatriz Ovalle. 
hechos acaecidos sino que consiste en una "capacidad productiva de dar vida a hechos que por la coherencia de su desarrollo, nos parezcan verosímiles" (Apocalípticos 223), creíbles, vale decir que pongan en juego una relación de "conformidad con un sistema de expectativas compartido habitualmente por el público" lector (El superhombre 17). Por lo mismo -concluye Ecola novela popular (en tanto "nieta del folletín" 2012: 19) se transforma en una 'máquina que mediante un accionar sinuoso, redundante y reiterativo produce gratificaciones; un estímulo que (por lo demás) no puede dejarse en manos del lector' (El superhombre 24) sino que es el mismo narrador quien le entrega la solución que espera", de manera tal que no lo complica ni lo conflictúa. Por el contrario, según Eco, la novela y los personajes conflictivos 'no reconcilian al lector consigo mismo: antes bien, le viene a plantear nuevos problemas' (El superhombre 19) e interrogaciones como estas: ¿Por qué queda impune el asesinato del Esclavo en La ciudad y los perros? ¿Por qué "las estirpes condenadas a cien años de soledad no tendrán una segunda oportunidad en la tierra?". Por lo tanto, en la novela popular 'el lector no debe hacer nada para que se verifique el desenlace consolatorio' ( $E l$ superhombre 24) como lo es aquella ilusión que sostiene a Alba mientras espera el regreso de Miguel, en La casa de los espíritus. Que 'el final gratificante no pueda dejarse al arbitrio del lector' está posibilitado porque -según advierte Martín-Barbero- el folletín "separa tajantemente a los héroes de los villanos aboliendo la ambigüedad y exigiendo al lector tomar partido", estrategia de recepción que es inducida a partir de la polarización de los personajes y del mundo narrado (La telenovela 75$)^{10}$. Como plantea Amar Sánchez, “[t]odas las formas de la cultura popular trabajan en el límite entre la convención y la novedad... Las estéticas de la modernidad (a la inversa de las clásicas) han sido muy severas con los productos de la cultura masiva por su condición serial y repetitiva" (1997: 47).

10 C. Goic, advierte que la polaridad de la historia de Martín Rivas se asemeja a las del "cuento de hadas" ("La novela chilena 1997: 45). Sin embargo, su adscripción al canon no le permite atender a las estrategias de compensación presentes en la novela, propias del folletín tradicional. 


\section{DEL FOLLETÍN A LA NOVELA POPULAR}

Resulta evidente que -a diferencia del canon-el corpus de la novela popular de filiación folletinesca no participa en el polo dominante del campo literario. A lo más, deviene en una alternativa de títulos a seleccionar frente a las lecturas, críticas y jerarquías preconizadas por el canon. Bourdieu señala que el canon determina "el grado de consagración específica (el «prestigio» literario y artístico)" de un autor. Por lo mismo, Bourdieu sostiene que "lo que está en juego en las luchas literarias es el monopolio de la legitimidad literaria" que permite a un escritor del canon "consagrar, obtener la adhesión cuando consagra a un autor o una obra" mediante un prefacio, una crítica laudatoria, un premio, etc. (1990: 16-19). Lo anterior deviene en que el canon se constituye como una restricción, como "repertorio selectivo". Sin embargo, como bien señala Chartier "hay en las obras ignoradas y marginadas algo que puede abrirlas a las reapropiaciones" (2006:149).

Respecto a la categoría de "novela popular" (que actúa como sinónimo genérico de folletín) no se trata aquí de lo "popular" en términos restrictivos sino en términos inclusivos y de accesibilidad sin fronteras a la producción, circulación, adquisición de un producto, tal como sucede en el marco de la cultura masiva que, en rigor -conforme al mercado- solo distingue a sus miembros atendiendo a la capacidad de consumo. Sin embargo, según Amar Sánchez "con la caída de las utopías vanguardistas cayó también la oposición entre arte y géneros masivos", considerados "amenos y poco problemáticos" (1997: 43-44). Conforme a Martín-Barbero, lo popular no remite ya "ni a pueblo ni a clase" sino a la sociedad de masas (De los medios 27 y ss.). Por su parte, García Canclini, en Culturas híbridas, enfatiza que se trata de una condición no limitada "ni a lo culto, ni a lo popular ni a lo masivo" (2005: 37). Como producto masivo, la narrativa popular transcurre por variados canales de producción y de circulación como el cine, la televisión, la radio, periódicos, revistas. Por lo mismo, su prestigio ("calidad") está regido por la premisa de "los más vendidos", los montos de las ventas y de las reediciones, todo lo cual otorga el rango genérico de best sellers. Según Martín-Barbero, "los procesos de constitución de lo masivo" son investigables "por fuera del chantaje culturalista que los convierte inevitablemente en procesos de degradación cultural" (2003: xxix). En tal sentido, respecto al folletín, no se trata de indagar en "lo que sobrevive de otro tiempo" (Cánovas 2002; Martín-Barbero 2003: xxx), sino lo que en el hoy hace que ciertas matrices culturales sigan teniendo vigencia, vale decir-glosando a Martín-Barbero-a 
partir de plantearnos una pregunta como esta: ¿Qué hace que una narrativa "anacrónica" conecte con la vida de la gente? (2003: xxx).

Para efectos de una respuesta preliminar, no debemos obviar que el canon de la narrativa chilena establece una relación de tensión y de exclusión con la novela de filiación folletinesca, pues no otorga mayor crédito al éxito que sus autores alcanzan entre sus lectores -no así en la academia- exclusión que limita analizar la novela popular conforme a las categorías propias derivadas de su extenso corpus. Menos, que se propicien y apliquen metodologías y teorías de análisis pertinentes a este (meta) género. Atender al "canon propio" de la novela popular guarda estrecha relación con el estado actual de los estudios culturales, con las revisiones teóricas y con las modificaciones que experimentan los estudios sobre la cultura, el discurso, el texto, la ficcionalidad, el canon, (Martín-Barbero 2003; Eco 1973, 2012; Herlinghaus 2002; Sarlo 1985; Mignolo 1992, 1995). Por lo mismo, lo que aquí denominamos "periferias, márgenes y fugas" de la literatura popular remite -entre otros aspectos teóricos- a los procesos de una inequívoca intertextualidad entre “corpus y cánones en contacto" presentes en la narrativa chilena.

Advirtamos que la novela popular lo es no porque resulte comprensible solo para el pueblo sino porque el fabricante de "intrigas sabe qué es lo que su público espera" o consume (Eco, El superhombre 22). A diferencia de la "novela problemática" que no deja al lector conforme con el desenlace, por ejemplo, Eco hace presente que la novela popular "debe provocar un tipo de crisis... que pueden ser resueltas" ilusoriamente, lo que convierte a la novela popular "en una máquina de producir gratificaciones ficticias"... "en un repertorio de soluciones consoladoras (a las crisis)"... tal y como el lector desea (El superhombre 23-24). Sin embargo, como hemos anticipado, las soluciones satisfactorias no necesariamente se cumplen en el variado y extenso corpus del folletín en Chile, en el cual prevalece la pérdida o la separación del objeto del deseo amoroso, entre otras alternativas de desenlaces. Lo que se mantiene en las novelas de tradición folletinesca, en la actualidad, es una densidad sentimental que establece una empatía con el lector, empatía que constituye el motor de su consumo, según el cliché de una premisa como "hacer llorar" (Eco, El superhombre 15) "inagotables ríos de lágrimas", "lacrimosidad" que es validada en Gracia y el forastero (García 2009: 7). Por lo demás, esta empatía con los receptores guarda directa relación con la estructura de la novela popular conforme a una singular disposición del mundo narrado en el cual las acciones se ordenan en torno a una "lógica/ sentimental" que no traza una "curva constante" sino un circuito "sinuosoidal (tensión, 
aflojamiento, nuevo aflojamiento)" (Eco, Retórica e ideología 112). Por lo mismo, se requiere prestar la debida atención a una lógica de las acciones guiada por el "imperio de los sentimientos" en que el amor "se convierte en un impulso narrativo prácticamente inextinguible" (Sarlo 1985). En el folletín, la acción emprende una trama incesante que deriva del tópico del "primer amor" o del "amor a primera vista". Tal motivo desencadena una dinámica emocional que se despliega narrativamente y cuya meta es la obtención del objeto del deseo (Brémond 1980; Greimas 1976). Por lo mismo, el advenimiento de un objeto del deseo amoroso no es indiferente a ninguno de los involucrados y en la novela popular de tradición folletinesca, el relato -liberado del apremio secuencial de las entregas semanales- avanza linealmente (o sinuosamente como en Cuatro Remos o en Adiós al Séptimo de Línea) hasta que se logra la correspondencia afectiva previa al surgimiento del obstáculo (de clase, etnia o de tipo político, por ejemplo). Y es el obstáculo el que proporciona el "carácter trágico y la grandeza a la acción" - dice Sarlo- pues se trata de "transgredir en nombre del sentimiento" o aceptar por frustrada una alianza inopinada que la sociedad no admite.

Según analiza Eco, en la novela de tradición folletinesca se trata de lograr una mimesis en la que se privilegie la ley de la verosimilitud, de lo creíble. Por lo mismo, se debe tener presente -como plantea Amar Sánchez-que "[1]os géneros populares, en sus formas canónicas, se caracterizan por cumplir rigurosamente las convenciones de sus fórmulas" (1997: 43), entre ellas, las de la acción, según hasta aquí hemos descrito. Tal como anticipamos, otra de estas fórmulas dice relación con los estereotipos que presiden la caracterización polar de los personajes "aboliendo la ambigüedad y exigiendo al lector tomar partido" (Martín-Barbero, La telenovela 73) como ocurre respecto a la imagen del "villano" Esteban Trueba en La casa de los espíritus. Por el contrario, cuando Martín Rivas es propuesto como un "protagonista digno de imitarse" (Blest Gana 1973: 14), se diseña un personaje típico que haga posible "una relación de goce entre el personaje y el lector" quien, en el proceso de la lectura, llevará a cabo un "reconocimiento (o una proyección) del personaje" como ejemplo para sí mismo (Eco, Apocalípticos 221). Este reconocimiento que se verifica en el lector como eje de la recepción, está fundado en una afinidad de intereses propia de la estrategia de la consolación.

A juicio de Amar Sánchez, la condición "seriada" y "repetitiva" del corpus de la novela popular proporciona a sus lectores "la sensación de lo familiar", al mismo tiempo que introduce mínimas variaciones con las que mantiene el interés del lector" y demarca su propio canon. En consecuencia, 
son "textos que no pueden alejarse demasiado de la fórmula pues corren el riesgo de que el lector los desconozca". Las estéticas posmodernas-concluye Amar Sánchez- proponen, en cambio, un nuevo modo de enfrentar la idea de repetición, incorporando un cierto trabajo de intertextualidad con las fórmulas y con los géneros" (1997: 43-44). Sin embargo, en la novela popular de tradición folletinesca también ocurre la ruptura intersticial de los cánones a los que se halla constreñida, conforme examinaremos brevemente.

\section{LA CASA DE LOS ESPIRITUS. NOVELA/FOLLETÍN: CONTINUIDADES Y RE-ESCRITURAS}

Advertimos que hacia la segunda mitad del siglo XX se acentúa un universo ficcional folletinesco en el cual la novela popular presenta un repertorio de soluciones evasivas y consoladoras dadas al lector en conformidad con un sistema de expectativas comunes, particularmente frente a las crisis históricosociales ocurridas en el país. Pasado el medio siglo, no es menor el efecto que -más allá del best seller-provocó Isabel Allende cuando en La casa de los espíritus (1982) ficcionaliza la historia social y política de la nación. Sin embargo, resulta un lugar común leer y analizar esta novela preferentemente desde el canon, como tributaria del realismo mágico de Cien años de soledad antes que como una actualizada escritura del texto de tradición folletinesca en Chile en el cual se reescriben sus formantes historiográficos, ficcionales y sentimentales.

A nuestro juicio, si bien resultan evidentes las relaciones intertextuales, temáticas y discursivas entre ambas novelas no se advierte suficientemente una distancia irónica -cuando no paródica-entre ellas. Por lo mismo, no se trata de reconocer afinidades entre un "ritmo narrativo y otro" (Rodríguez 1986) presente, por ejemplo, en la apertura de estas novelas, sino de releer las distancias y el acercamiento de sus componentes discursivos que se ponen de manifiesto. Por ejemplo, Rosa del Valle no es estrictamente la Bella Remedios Buendía. Si bien esta heroína posee una extraña belleza, no irradia un perfume que enamore a todos los hombres: ella es la novia oficial de Esteban Trueba a quien espera mientras éste busca oro en el norte del país. Remedios asciende virginalmente a los cielos mientras que el destino hace que Rosa muera accidentalmente envenenada y posteriormente sea víctima de una bárbara autopsia y de un acto de necrofilia. Y es en este punto donde se sitúa parte del locus narrativo de Isabel Allende: contradecir, 
parafrasear aspectos del canon de García Márquez, pues "la esplendorosa desnudez de sirena de Rosa" (45) dejará paso a la exposición del trato con un cuerpo muerto, no sacralizado, ni virginal, ni reducido estrictamente a lo mágico ${ }^{11}$. Es así como I. Allende disocia la hibridez del realismo mágico descomponiendo la dualidad magia/mito vs prosaísmo/ realidad, conforme a lo cual propicia un arduo trabajo de la memoria y de la escritura efectuado por Clara y que concluye con la exégesis de Alba, su nieta: todo "corresponde a un destino dibujado antes de mi nacimiento y Esteban García es parte de ese dibujo..." (452-453). No se trata, pues, de que "las estirpes condenadas a cien años de soledad" no tendrían derecho a la felicidad del amor ni a otra oportunidad en la vida. En I. Allende, la fatalidad de lo cíclico obedece a una dualidad sentimental en que participan 'la sangre, el dolor y el amor' en una radical alteridad individual y social que despliega y repliega una espantosa y reversible cadena de violaciones y de víctimas. Se trata de una escritura que no se reduce a la compensación sentimental sino que se emprende como terapia para "sobrevivir a los espantos" sentimentales, políticos y sociales.

Doris Sommer advierte que particularmente en la novela del siglo XIX, "[1]as relaciones amorosas y sus finales generalmente felices actúan como representaciones en las que el erotismo y el nacionalismo se convierten en figuras retóricas y en las que la relación recíproca entre la pasión heterosexual y los estados hegemónicos funcionan como mutua alegoría" (Novelas fundacionales 48). Estos finales felices -que muestran alianzas entre niveles sociales diferentes al modo de Martín Rivas-sufren una inversión en el siglo $\mathrm{XX}$ lo que da énfasis al motivo del amor impedido por cuestiones de calidad social, política o étnica. Los del Valle y los Trueba pueden aliarse por razones de prestigio y de afinidad social y política (como aquella entre liberales y conservadores) de modo tal que el matrimonio de sus hijos parece destinado a la felicidad ${ }^{12}$. Sin embargo, el examen del linaje Trueba/del Valle muestra

11 La autopsia de Rosa es efectuada en una prosaica mesa de la cocina "donde la Nana amasaba el pan y picaba las verduras" (44-45) recurriendo a "siniestros instrumentos" (46) y terminará "siendo cosida como un saco" (46). Clara es testigo de este episodio traumático de modo tal que la novela termina reconfigurando su propio canon histórico-sentimental mediante una estructura dual que muestra precisas reversiones de lo dado en Cien años de soledad.

12 Según pone de relieve J. Bengoa "bajo la estrategia del amor, como elemento desencadenante de la relación conyugal o de la amistad, como factor de compadrazgo o de relaciones parentales, se esconden secretas leyes de "matrimonios preferenciales", endogámicos, sistemas de parentesco (y etnia), alianzas e intereses" (2006: 85). Conforme a este circuito 
un continuo deterioro. Las mujeres Trueba sucumben ante la atracción que los jóvenes del campesinado ejercen sobre ellas, lo que genera alianzas sentimentales moralmente lícitas pero no permitidas socialmente, como analizaría Sarlo. Por esta vía, este motivo amoroso da cuenta de dos polos que se atraen pero que son impedidos por las normas del poder hacendal: un terrateniente puede poseer a una mujer campesina pero un inquilino no puede hacer lo mismo con la hija de su patrón ${ }^{13}$. Lo notorio es que en $L a$ casa de los espíritus el motivo del amor impedido por cuestiones de clase aparece potenciado por un factor ideológico sustentado en una renovada doctrina social de la Iglesia ${ }^{14}$.

Tal viene a ser la dinámica de la pasión y del "imperio de los sentimientos" que (desde el folletín) funciona como "mutua alegoría" -al decir de Sommeren La casa de los espíritus. Conforme a la fórmula de la novela popular de tradición folletinesca, el típico cauce consolador se verifica mediante un final a medias feliz: Trueba intercede por un "revolucionario" y libera a su nieta de los torturadores. A su vez, Alba termina siendo la heroína ultrajada que escribe mientras espera el regreso de Miguel $^{15}$. Por esta vía, La casa de los espíritus consolida un indiscutido canon de la novela popular que se caracteriza por una precisa matriz de significados folletinescos, historiográficos, populares, políticos y sociales que difiere de la alianza campo-ciudad que predomina en Golondrina de invierno de V.D. Silva (1912), por ejemplo, o

inter pares, las relaciones de Esteban Trueba con las mujeres campesinas se deben comprender como transgresiones permitidas por una pax hacendal que no implican necesariamente una conflictividad social sino un imaginario o autoimagen de una clase que, por tradición, se arroga la representación de la Nación, se asume a sí misma como propietaria (Bengoa 85) y que cautela el derecho de facto de unos sobre otros y en un indiscutido poder de patronazgo que -más allá del mestizaje- redunda en las secuelas de la bastardía.

13 Se trata de un motivo propio del imaginario popular de carácter folclórico-social que se expresa en canciones como "Corazón de escarcha" o en "La madre del cordero".

14 Doctrina social cristiana que se resume en que "los pollos y las gallinas pueden vencer al zorro que los devora" y en que "la Santa Madre Iglesia está a la derecha, pero Jesucristo siempre estuvo a la izquierda" (2002: 193).

15 Cánovas destaca que Isabel Allende "ha logrado otorgarle prestigio literario al testimonio rosa..." de modo que "en La Casa de los espíritus el realismo maravilloso y la tradición naturalista dialogan con el reportaje testimonial y el melodrama"... logrando "una obra literaria de tanto impacto social y cultural como los folletines romántico-sociales del siglo XIX" (Los espiritus literarios 1988: 14-15). J. M. Oviedo, también reconoce la filiación folletinesca de Isabel Allende al señalar que ha dado "nueva vida y función a la literatura sentimental" (2001: 386). 
de los tradicionales procedimientos del folletín de filiación histórica, según se ilustra en el desenlace de 1981: Entre el fulgor y la agonía (1991) de Juan Gabriel Araya. Conforme a Eco, "además de su vocación populista, la dinámica incitación-solución" del conflicto "convierte a la novela popular en todo un repertorio de denuncias de las graves contradicciones de la sociedad $\mathrm{y}$, al mismo tiempo, en un repertorio de soluciones consoladoras a las crisis" (El superhombre 23).

\section{UN FOLLETÍN DENTRO DE UNA NOVELA}

Aunque Darío Oses ha declarado su afición al folletín (Guerrero 1995) y este formato está presente en El viaducto (1994), la crítica ha prestado más atención a los referentes historiográficos de esta novela (Moreno 2000), al tópico de los perdedores, de aquellos que no se dan por vencidos ni quieren sobrevivir entre los vencedores (Amar 1997) o a los problemas que han planteado los primeros años de la re-democratización liberal-económica (Gariboto 2008). Sin embargo, la propuesta de una novela como esta es que no sea leída al margen de su filiación histórico-folletinesca. No en vano, El viaducto reproduce la estructura de un "folletín dentro de una novela". En ella asistimos a la escritura, lectura, puesta en escena, actuación y filmación, en el año 1973, de una teleserie sobre el gobierno de J. M. Balmaceda, que deviene en una parodia de las tradicionales seriales chilenas con pretensiones históricas. Por lo demás, su contra-correlato discursivo es la metalengua del folletín frente a las expectativas de la tradicional novela de filiación histórica. Si para Eco la novela popular es una "máquina de producir gratificaciones" (El superhombre 24), para el guionista, la teleserie es "una locomotora con los frenos malos. (1994: 29,30). En este folletín televisivo se genera un dinamismo desenfrenado que no descansa estrictamente en sus referentes historiográficos sino, más bien, en una intencionada carnavalización de la época, que da cuenta del año 1973 como un "cómico presente, de un triunfalismo endeble" (28) en tanto que la intriga relativa al año 1891 es sometida a un curso redundante y sinuoso en el cual "los diversos elementos de la intriga se acumulan hasta crear una tensión máxima que el desenlace hará estallar” (Retórica e ideología 112). Se genera, así, una reescritura del folletín tradicional para poner de revés su canon y situarlo en línea con una matriz sacrificial (Oses, El gato con botas 2004) más allá de la autocomplacencia y de los imaginarios del lector/ espectador (Oses, La experiencia 1995). De este modo, el texto televisivo 
actúa como un pretendido espejo de una novela tradicional que transcurre en el año 1973. Pero, el guión no actúa como una compensación del presente sino como su contra-relato, su polémico revés. No se trata, entonces, de que este "viaducto" sea simplemente un puente que conecte el país. Es también la conexión entre discursos, sujetos, lugares y épocas incompatibles entre sí: entre la novela del 73 y el folletín historiográfico sobre 1891; entre la historia y la metaficción historiográfica; entre la ficción, los sujetos reales y los actores que interpretan papeles hiper-sentimentales, nada de heroicos. Por lo mismo, la trama del guión deviene en una parodia del mundo del folletín tradicional, por cuanto, "el imperio de los sentimientos" propios del género (Sarlo 1985) queda sometido, irónicamente, a un contexto político meta-historiográfico y a una carnavalización de las leyes textuales de los estereotipos del folletín que Oses identifica con el "martín arribismo"16. Pero, no se trata aquí solo de un guión seriado sino de un texto desjerarquizado, desmadejado, como "una cosa de locos". "Nadie sabe dónde empieza ni dónde termina" (1994: 20), se afirma. En el guión televisivo prima un fatum que representa el destino infausto que contempla la trama y la teje a su medida, fatalidad folletinesca que, sin embargo, cede lugar a un giro utópico al dar paso a la transcripción de un discurso historiográfico de Balmaceda -que actúa como contratexto del legado de Salvador Allende, respecto a que "se abrirán las amplias alamedas"- con lo cual se supera la perspectiva grotesca y hace presente el marco histórico-político del proyecto de 1973.

16 En un sinuoso guión folletinesco, Gustavo Salazar representa el "martin-arribismo" que critica Oses. A pesar de la ruina de su padre, hacia 1891, Gustavo ha podido titularse de ingeniero, gracias al mecenazgo de Recaredo Aguirre quien, además, lo acepta como novio de su hija Beatriz. Y es ante estas expectativas de felicidad que surgen los obstáculos, propios del amor imposible. Un Don Juan capitalino apuesta a que seducirá a la novia para lo cual arruina a Isidro Aguirre quien deberá consentir en que al aval de ellas sea Beatriz. Tal es la fórmula exacerbada de esta ficción folletinesca a la cual se yuxtapone una especularidad melodramática e historiográfica: todos los personajes morirán en el curso de la guerra civil y Beatriz se convertirá en la amante de un oficial rebelde. Ella discute el modelo sacralizador y estereotipado de los personajes del folletín: "las heroínas de las teleseries tienen que ser niñas buenas, enfermas de románticas"... pero, no por eso deben ser “enfermas de huevonas" (91). 


\section{CONCLUSIONES}

Conforme a nuestro estudio, podemos concluir que la práctica de la escritura folletinesca no es ajena -en diverso grado- a los fundadores de nuestra narrativa. Notorio es que los narradores del siglo XIX propiciaron diversos e innovadores motivos con o sin el formato del folletín, como aquellos del amor impedido por razones sociales, circunstancias histórico-políticas o de exclusión étnica, en el marco del imaginario folletinesco de la novela liberal que -conforme a diversas variantes- se hace extensivo hasta el siglo XX y actúan como una estructura modélica para un gran sector de la narrativa chilena.

Sin embargo, esta serie aparece señalada con un signo de interdicciones éticas y estéticas que la sitúan al margen del canon literario nacional, pues se la reduce a una ficción sentimental que pone en escena la intensidad de la pasión amorosa, el destino fatal, el estereotipo de los personajes, la inverosimilitud. Tales rasgos genéricos determinan la condición marginal de un (meta) género que, a nuestro parecer, no ha provocado mayores reflexiones teórico-metodológicas como las que, inicialmente, hasta aquí hemos expuesto, destinadas a definir su canon frente a la novela nacional que propiciaba la elite intelectual de la generación literaria de 1842 o en las diversas generaciones del siglo XX, por ejemplo. A lo más, se concuerda en la índole y el valor de una escritura subestimada como "una narratividad degradada" (Eco 2012: 26).

Por lo mismo, conforme a lo planteado hasta aquí, podemos concluir que el análisis de un corpus representativo - como el que hemos descrito-pone de relieve los procesos de continuidades y rupturas que experimentan la estructura del mundo narrado y los imaginarios propios de la actual novela popular con respecto a la serie folletinesca y al canon de la novela nacional. Considerando los aportes de los estudios culturales y mediacionales, particularmente de Eco (2012), Herlinghauss (2002), Martín- Barbero (1987), Sarlo (1985) y Sommer (2004), estimamos que es posible formalizar los rasgos de una narrativa que ha sido estereotipada como una singular semiosis sentimental portadora de un previsible e ingenuo mundo narrado, fácil de decodificar, que se encuentra situada al margen de la novela problemática o conflictiva, como describe Eco (2012). Conforme a tales juicios, se trataría de una narrativa que solo interesa como reproducción de un masivo mercado autorial-editorial ajeno a los procesos de formación y consolidación de una nación, de sus precedentes fundacionales y de sus utopías, distopías y traumas político-sociales. Por lo mismo, para los efectos de la constitución del canon de la narrativa chilena 
concluimos en que es preciso reexaminar la reducción y calificación de la narrativa de filiación folletinesca que la limita a procesos compensatorios o no compensatorios de las expectativas del lector como un hecho que no guardaría relación con las modificaciones globales producidas en el seno de la institucionalidad literaria y su correspondiente canon y metalengua.

Concluimos, también, que si atendemos al programa de D'Halmar, la pugna entre las "mentirosas historias sentimentales" $(1952$ : 143, 256) y los "romances reales" no se resuelve únicamente con la mirada de soslayo que el canon lanza sobre el folletín. En La casa de los espíritus, por ejemplo, el "universo de tramas sinuosas" del linaje Trueba y el "imperio de los sentimientos" que avasalla a Clara, Blanca y Alba no se reducen a que el amor sea reprimido y sentenciado a "cien años de soledad". La nieta escribe para interpretar y comprender el curso violento de su linaje con la intención de conjurar la tradición del canon positivista-naturalista (todo "corresponde a un destino dibujado antes de mi nacimiento y Esteban García es parte de ese dibujo...") (452-453) y oponerle -aunque parcialmente- una compensación sentimental de matriz romántica que actúe como terapia para "sobrevivir a los espantos" sentimentales, socio-políticos e historiográficos.

Igualmente, podemos concluir que en su formato de novela popular, la serie de tradición folletinesca no es solo un tipo de escritura ("anacrónica") destinada a lectores masivos y nostálgicos por los imaginarios decimonónicos (Cánovas 2002: 267). Según hemos desarrollado hasta aquí, nuestra conclusión es que se trata de un imaginario cultural con una estructura distintiva que no se limita a hacer llorar o a compensar al lector con los desenlaces que este espera, sino que puede llegar a examinar sus propias estrategias de ficcionalidad, según hemos descrito respecto a El viaducto.

En consecuencia, según dijimos inicialmente, es preciso considerar el examen de una "vía chilena del folletín" que-conforme a un variado formato y a una actualizada reescritura de sus motivos e imaginarios característicospropicia una práctica de la consolación no ajena a cuestiones sociales, políticas y utópicas, ni a la carnavalización o desacralización del género. Poner atención a estas interacciones entre el canon y el corpus, entre el centro y la periferia, constituye un punto de partida respecto a la pregunta que se hace Martín-Barbero con relación a ¿qué hace que "ciertas matrices culturales sigan teniendo vigencia" y conecten "con la vida de la gente" (2003 xxx.)? En último término, nuestras conclusiones apuntan a que un sistemático análisis de los procesos escriturales del folletín y de su público lector en Chile-siglos $\mathrm{XIX/XX-hace} \mathrm{posible} \mathrm{una} \mathrm{"ampliación} \mathrm{del} \mathrm{campo} \mathrm{cultural,} \mathrm{en} \mathrm{que} \mathrm{se} \mathrm{realiza}$ 
finalmente a un nivel extenso, con el concurso de los mejores, la circulación de un arte y una cultura popular" (Eco, Apocalípticos 12) a partir de lo cual se establecen nuevas matrices de sentidos derivadas de renovadas interacciones comunicacionales, mediacionales y culturales.

\section{BIBLIOGRAFÍA}

Allende, Isabel. La casa de los espíritus. Barcelona: Planeta, 2002.

Inés del alma mía. Buenos Aires: Sudamericana, 2006.

Amar Sánchez, Ana María. "Canon y traición: Literatura vs cultura de masas”. Revista de Crítica Literaria Latinoamericana 45 (1997): 43-53.

Araya, Juan Gabriel. 1891: Entre el fulgor y la agonía. Santiago: Universitaria, 1991

Arcos, Carol. "Novelas, folletín y la autoría femenina en la segunda mitad del siglo XIX en Chile". Revista Chilena de Literatura 76 (2010): 27-42.

Barraza, Eduardo. "El beso de la mujer araña: elocución y diseño". Estudios Filológicos 23 (1988): 25-34.

"La monja alférez de José Victorino Lastarria: oscilaciones metaficcionales". Anales de Literatura Chilena 18 (2012): 37-50.

"La novela liberal: liberalidades de la novela". De La Araucana a Butamalón. El discurso de la conquista en la literatura chilena. Valdivia: U. Austral, 2004. 178-192.

"De parlamentos, el amor y la guerra en la conquista de Arauco". Taller de Letras NE3 (2013): 35-46.

"Texto/Nación: un sistema de inclusiones y de exclusiones de la novela liberal". Adelantados y escrituras de la conquista. Santiago: U. de Santiago, 2013. 161 y ss.

“"'Desde que un día leyendo a Balzac”: Novela/folletín en las novelas fundacionales de Alberto Blest Gana". Alpha 40 (2015): 37-52.

Barros Grez, Daniel. Cuatro Remos. 1883. Santiago: Quimantú, 1971.

Bello. Tomo I (1810-1859), 1999. Tomo II (1860-1879), 2001.

Textos fundacionales de la narrativa chilena. Desde la Aurora de Chile (1812) hasta la Sociedad Literaria (1842). Estocolmo: Senda, 2009.

Bengoa, José. La comunidad reclamada. Santiago: Catalonia, 2006.

Blanco, Guillermo. Gracia y el forastero. 1964. Santiago: Zig-Zag, 2009, 74 ed. Prólogo de César García (7-14).

Blest Gana, Alberto. "Literatura chilena. Algunas consideraciones sobre ella". Testimonios y documentos de la literatura chilena. Comp. José Promis. Santiago: Nascimento, 1977.

Martín Rivas. Santiago de Chile: Quimantú, 1973.

Durante la Reconquista. Santiago de Chile: Zig-Zag, 1951.

Mariluán. (1862). Santiago de Chile: LOM, 2005. 
Bourdieu, Pierre. "El campo literario. Prerrequisitos críticos y principios de método". Revista Criterios 25-28 (enero1989 - diciembre 1990): 20-42.

Boyer, A. M. La paralittérature. Paris: Presses Universitaires de France, 1992. Frontiéres du littéraire. Paris: Université de Paris-IV-Sorbonne, 1995.

Brémond, Claude. "La lógica de los posibles narrativos". Introducción al análisis estructural del relato. Comp. Roland Barthes, et al. Buenos Aires: Nueva Visión, 1980.

Cabello Pino, Manuel. Motivos y tópicos amatorios en "El amor en los tiempos del cólera". Huelva: Universidad de Huelva, 2010.

Cánepa, Gina. "Folletines históricos del Chile independiente y su articulación con la novela naturalista". Hispamérica 50 (1988): 23-34.

Cánovas, R. Novela chilena. Nuevas generaciones. Santiago: Universidad Católica, 2002.

"Los espíritus literarios y políticos de Isabel Allende". Revista Chilena de Literatura 32 (1988): 119-125.

Chartier, Roger. Cultura escrita, literatura e historia. México: F.C. E., 2006.

Darío, Rubén y Eduardo Poirier. Emelina. 1886. Santiago: RIL, 2007.

D'Halmar, Augusto. Juana Lucero. Santiago: Nascimento, 1952.

Eco, Umberto. Apocalípticos e integrados ante la cultura de masas. Barcelona: Lumen, 1973. El superhombre de masas. Barcelona: Ramdom House Mondadori, 2012.

"Retórica e ideología en Los Misterios de París, de Eugéne Sue”. Sociología de la creación literaria. Goldmann. Lucien et. al. Buenos Aires: Nueva Visión, 1968. 99-126.

Ferreras, Juan Ignacio. La novella por entregas 1840-1900. Madrid: Taurus, 1972.

Foresti, Carlos, Eva Löfquist y Alvaro Foresti. La narrativa chilena. Desde la Independencia hasta la Guerra del Pacífico. Tomo I (1810-1859). Santiago: Andrés Bello, 1999.

La narrativa chilena. Desde la Independencia hasta la Guerra del Pacífico. Costumbres e historia. Tomo II (1860-1879). Santiago: Andrés Bello, 2001.

García Canclini, Néstor. Culturas híbridas. Buenos Aires: Paidós, 2005.

Lectores, espectadores, internautas. Barcelona: Gedisa, 2007.

García Márquez, Gabriel. Cien años de soledad. Santiago: Sudamericana, 1993.

Garibotto, Verónica. Contornos en negativo: Reescrituras posdictatoriales del siglo XIX (Argentina, Chile, Uruguay). Pittsburg: University of Pittsburg, 2008.

Goic, Cedomil. La novela chilena. Santiago: Universitaria, 1997.

"Brevísima relación de la historia de la novela hispanoamericana". La novela hispanoamericana. Descubrimiento e invención de América. Valparaíso: Ediciones Universitarias de Valparaíso, 1973. 9-5.

Greimas, J. A. Semántica estructural. Madrid: Gredos, 1976.

Guerrero, Pedro Pablo. "Darío Oses: "Me encanta el folletín”". El Mercurio, Revista de Libros (18 de Julio 1995): 2,3.

Herrera, Karla. "Folletín Literario de La Unión de Valparaíso (1885-1925)". Tesis de Licenciatura. Universidad Católica de Chile, 1998. 
Inostrosa, Jorge. Adiós al Séptimo de Línea. Santiago: Zig-Zag, 2011.

Lafourcade, Enrique. Palomita Blanca. 1971. Santiago: Zig-Zag, 2007.

Larraín, Raimundo. Cailloma. Leyenda Indiana. Santiago: El Independiente, 1870.

Lira, Máximo. A orillas del Bío-Bío. Escenas de la vida araucana / Gualda. Santiago: El Independiente, 1870.

Marchant Lazcano, Jorge. La Beatriz Ovalle. Santiago: Renacimiento, 1983.

Martín-Barbero, Jesús. "La telenovela desde el reconocimiento a la anacronía". Narraciones anacrónicas de la modernidad. Melodrama e intermedialidad en América Latina. Hermann Herlinghaus. Santiago: Cuarto Propio, 2002. 61-78.

De los medios a las mediaciones. Colombia: Convenio Andrés Bello, 2003.

Matus, Álvaro. "Best sellers chilenos. El canon bastardo", en El Mercurio, Revista de Libros (Diciembre 17 de 2004).

Mignolo, Walter. "Second Thoughts on canon and corpus". Latin American Literary Review 20, 40 (1992): 66-69.

"Entre el canon y el corpus: alternativas para los estudios literarios y culturales en y sobre América Latina. Nuevo texto crítico (julio 1994 - junio 1995): 23-36.

Millet, Kate. "El amor ha sido el opio de las mujeres". (Entrevista). El País, mayo 211984.

Moreno, Fernando. "Chile 1891-1991: de la historia a la novela en torno a El viaducto de Darío Oses". 1898-1998, fines de siglo, historia y literatura hispanoamericanas. Poitiers: Actas Centre de Recherches et d'Études sur 1'Amerique Iberique, 2000. 147-162.

Oses, Darío. El viaducto. Santiago: Planeta, 1994.

"El gato con botas". Santiago: Proyecto Patrimonio, 2004.

"El viaducto: la experiencia de escribir una novela sobre dos crisis históricas". Revista Chilena de Humanidades 16 (1995): 85-91.

Oviedo, J. M. Historia de la literatura hispanoamericana. Madrid: Alianza, 2001.

Poblete, Juan. Literatura chilena del siglo XIX: entre públicos lectores y figuras autoriales. Santiago: Cuarto Propio, 2003.

Poblete V., Hernán. Genio y figura de Alberto Blest Gana. Buenos. Aires: EUDEBA, 1968.

Puig, Manuel. El beso de la mujer araña. Barcelona: Seix Barral, 1988.

Rodríguez, Mario. "García Márquez/Isabel Allende: relación textual”. Los libros tienen sus propios espiritus: Estudios sobre Isabel Allende. Ed. Marcelo Coddou. México: Universidad de Veracruz, 1986.

Rodríguez Monegal, Emir. "El folletín rescatado". Revista de la Universidad de México n², (octubre) 1972. 25-35.

Rosasco, José Luis. Donde estás, Constanza. 1980.; El metrogoldin; Francisca, yo te amo. 1988.; La niña azul. 1997. Santiago: Andrés Bello, 2004.

Sánchez, L. A. Proceso y contenido de la novela hispano-americana. Madrid: Gredos, 1976.

Sarlo, Beatriz. El imperio de los sentimientos. Buenos Aires: Catálogo 1985.

Silva Castro, Raúl. Panorama literario de Chile. Santiago: Universitaria, 1961.

Silva, Víctor Domingo. (1912). Golondrina de invierno. Santiago: Nascimento, 1971. 
El Mestizo Alejo. Santiago: Zig-Zag, 1985.

Solar, Alberto del. "Huincahual". Obras Completas. París: Garnier Hermanos, 1888.

Sommer, Doris. Novelas fundacionales de Hispanoamérica. México: F.C.E., 2004.

"Un círculo de deseo: los romances nacionales en América Latina". Araucaria. Revista Iberoamericana de Filosofía, Política y Humanidades 16 (2006): 3-22.

Zó, Ramiro Esteban. "Funciones de la novela sentimental hispanoamericana durante el siglo XIX”. CILHA - a. 8 n. 9 - 2007. 